\title{
Bullying na perspectiva de adolescentes que cometeram ato infracional
}

\author{
Bullying in the perspective of teenagers who had committed offenses
}

Thiago Osório Comis ${ }^{[a]}$, Aline Cardoso Siqueira ${ }^{[b]}$

\footnotetext{
${ }^{\text {[a] }}$ Psicólogo formado pelo Centro Universitário Franciscano, Santa Maria, RS - Brasil, e-mail: tiagoosorio@yahoo.com.br

${ }^{[b]}$ Doutora em Psicologia pela Universidade Federal do Rio Grande do Sul (UFRGS), professora adjunta do curso de Psicologia do Centro Universitário Franciscano, Santa Maria, RS - Brasil, e-mail: alinecsiq@gmail.com
} [c]

Recebido: $12 / 03 / 2011$ Received: 03/12/2011

\section{Resumo}

A violência entre pares tem sido considerada há muito tempo um significante problema social com consequências potencialmente sérias para agressores e vítimas. Assim, o impacto do bullying pode ser devastador, visto que os perpetradores podem desenvolver comportamento antissocial e as vítimas podem até cometer suicídio. 0 objetivo deste estudo foi investigar o fenômeno bullying em adolescentes que cumprem medida socioeducativa. Foi realizada uma entrevista com cinco adolescentes, de 16 a 17 anos, que cumpriam medida socioeducativa de liberdade assistida. Entre os resultados destaca-se que todos já haviam se envolvido em algum episódio de bullying, tendo assumido o papel de agressor, vítima ou testemunha, e demonstrando flexibilidade dos papéis no fenômeno. Os jovens não apresentaram clareza sobre o que é o bullying, contudo, estavam cientes dos danos causados por essa violência. Programas de intervenção nas escolas que favoreçam a comunicação entre os jovens, os professores e as famílias, o esclarecimento sobre o bullying e suas consequências, bem como a construção de estratégias efetivas de enfrentamento do fenômeno são necessários.

Palavras-chave: Bullying. Vitimização. Comportamento infrator.

\begin{abstract}
Violence among peers has long been considered a significant social problem with potentially serious consequences for aggressors and victims. The impact of bullying can be devastating, because the perpetrators can develop antisocial behavior and the victims can commit suicide. This study aimed to investigate the phenomenon of bullying among adolescents who comply with socioeducative measure. We performed a semi-structured interview with five teenagers, aged between 16 and 17 years, who met as socioeducative of parole. Among the results, it is emphasized that everyone had already got involved in one episode of bullying, either being the aggressor, victim or witness, which means flexibility of performances. The young people do not show to know clearly what bullying means, although they are conscious about the damage caused by this violence. Intervention programs in the school that work on communicate between young people, teachers and family about bullying and its consequences as well as how build effective strategies for handle this phenomenon are necessary.
\end{abstract}

Keywords: Bullying. Vitimization. Offense behavior. 


\section{Introduç̃̃o}

O bullying é um problema crescente nos dias de hoje, porém, tem sido dificilmente identificado por pais e escolas em razão de suas características, que, muitas vezes, são confundidas com dificuldades que as crianças e os adolescentes enfrentam durante essas fases do desenvolvimento (Almeida, Silva, \& Campos, 2008; Francisco \& Libório, 2008). 0 termo bullying, que não possui tradução literal para o português, refere-se à violência entre pares, com grande destaque para a ocorrência no âmbito escolar (Santos \& Grossi, 2008). Esse fenômeno se caracteriza por atitudes de violência, tanto verbal quanto física, nas quais esses comportamentos negativos são repetitivos e intencionais. Os envolvidos são crianças e/ou adolescentes em desequilíbrio de poder, e essas atitudes podem atingir psicologicamente ou fisicamente as vítimas (Almeida, Lisboa, \& Caurcel, 2007; Almeida et al., 2008; Fekkes, Pijpers, \& Vanhorick, 2004; Neto, 2005). Dado o impacto da vivência desse fenômeno no desenvolvimento, torna-se relevante aprofundar o conhecimento sobre o tema a fim de propor estratégias de prevenção e combate ao bullying.

\section{Características e efeitos do bullying}

A busca pela compreensão dos fatores que envolvem o bullying pode ajudar a identificar os efeitos negativos nos jovens envolvidos, tanto a curto como a longo prazo. A curto prazo as vítimas podem apresentar queixas como cefaleia, dores abdominais, dores de garganta, náuseas, vômitos, anorexia, enurese, distúrbios escolares, tristeza e insônia. Para os pais e para a escola, esses indícios parecem problemas corriqueiros, mas, na verdade, podem ser indicadores da ocorrência de bullying (Cho, Hendrickson, \& Mock, 2009; Esperon, 2004). A longo prazo os efeitos podem ser mais intensos e comprometedores. Crianças e adolescentes podem ter tendências violentas e, até mesmo, desenvolver comportamento infrator quando sofrem bullying nessas faixas etárias (Cullen, Unnever, Hartman, Turner, \& Agnew, 2008; Guerra, Williams, \& Sadek, 2011). Ademais, algumas pesquisas evidenciam uma correlação entre o bullying e atitudes criminosas aos 20 anos de idade, sendo que a maioria que praticou bullying ativamente teve uma condenação por crime (Barker, Arseneault, Brendgen, Fontaine, \& Maughan, 2008; Esperon, 2004).

$\mathrm{O}$ bullying pode se apresentar de forma direta e indireta. A forma direta se dá de maneira mais explícita, por meio de apelidos, ameaças e agressões, entre outros ataques abertos à vítima. Já a indireta é de difícil detecção, por se tratar de agressões mais sutis como caretas, gestos obscenos e manipulação do grupo para isolar um determinado colega nas atividades ou no convívio escolar, entre outras (Xavier, 2008).

Os indivíduos envolvidos no bullying podem ser ativos ou passivos. Os indivíduos ativos apresentam, geralmente, um histórico de contestação das regras escolares, mais necessidade de controlar as situações pelo poder, autoestima elevada e algum tipo de violência física perpetrada por um cuidador (Xavier, 2008). Esses também se caracterizam pela agressividade, tanto na escola, com colegas, professores e funcionários, como fora dela, com familiares e pessoas de seu convívio social. Outro tipo de agressor que merece destaque é o agressor secundário, pois possui o papel de cúmplice de quem toma a iniciativa das agressões, repete o comportamento agressivo ou obedece às ordens do agressor principal, que serve de modelo para os outros alunos, que o veem como o destemido, o líder, o "valentão" (Xavier, 2008). Já os indivíduos passivos tendem a possuir um círculo de amizade pequeno, baixa autoestima, ansiedade, passividade, depressão e os pais costumam ser superprotetores (Esperon, 2004).

A Associação Brasileira Multiprofissional de Proteção à Infância e à Adolescência (ABRAPIA) também descreve uma classificação do bullying, relacionada ao papel desempenhado pela criança ou adolescente perante esse tipo de comportamento (ABRAPIA, 2007). Entre os papéis, têm-se os alvos, alvos/autores, autores e testemunhas do bullying. Os autores do bullying, normalmente, são componentes de famílias com pais que não exercem apoio significativo à prole e possuem pouca empatia. Os alvos têm como característica a insegurança e a baixa autoestima, geralmente, não possuem status ou recursos, reagem passivamente às agressões, têm poucas amizades e sua sociabilidade é reduzida. E as testemunhas, normalmente, sentem-se incomodadas com as situações de agressão, mas não reagem por temerem se tornar alvos ou por não saberem a quem recorrer (ABRAPIA, 2007). 
Os personagens envolvidos no bullying podem sofrer consequências imediatas e/ou tardias. Dessa forma, os perpetradores podem se tornar adultos com comportamentos antissociais, chegando a cometer atos criminosos. As vítimas podem apresentar baixo desempenho escolar, por simular doenças para não frequentar a escola, além de sintomas depressivos, que, muitas vezes, levam ao suicídio. $\mathrm{E}$ as testemunhas também podem desempenhar negativamente sua capacidade acadêmica e social (Almeida et al., 2008; Neto, 2005; Xavier, 2008). 0 comportamento agressivo vivenciado pelas crianças e adolescentes em suas famílias e no seu convívio social pode servir de referência em posteriores condutas agressivas, como no caso do bullying contra seus pares. E o bullying, por sua vez, trará consequências que podem se refletir em algum tipo de comportamento infracional (Xavier, 2008).

\section{Bullying e ato infracional}

O comportamento de um indivíduo é determinado por sua personalidade, e que esta é formada por traços que são mais ou menos intensificados ou ampliados pelas situações vividas durante o desenvolvimento de cada um. Muitas situações negativas vivenciadas podem causar sofrimento ao sujeito e, caso esse sofrimento tenha uma duração prolongada e esteja associado a comportamentos agressivos, poderá desencadear na vítima diversos transtornos de personalidade. 0 bullying, por exemplo, pode ser considerado um dos fatores desencadeadores de alguns distúrbios psicológicos, como o transtorno desafiador opositivo e o transtorno de conduta (American Psychiatric Association [APA], 2002; Gallo \& Williams, 2008).

0 transtorno desafiador opositivo apresenta características agressivas como violação de normas ou regras sociais, dificuldade de socialização, envolvimento precoce com drogas, comportamento antissocial, impulsividade, humor depressivo, tentativas de suicídio, ausência de sentimento de culpa, hostilidade, destruição de patrimônio público, entre outras (APA, 2002; Gallo \& Williams, 2008). Já o transtorno de conduta tem características semelhantes às do transtorno desafiador opositivo, na qual os direitos de outro indivíduo e as regras sociais não são respeitados. Deve-se ressaltar que essas classificações só serão válidas caso os comportamentos estejam presentes por pelo menos seis meses (APA, 2002). As pessoas acometidas por esses transtornos não se sentem responsáveis por seus atos e, frequentemente, não compreendem o sofrimento e o sentimento alheio, porém, possuem uma grande capacidade de observar e reconhecer a fragilidade em uma possível vítima (Xavier, 2008). Assim, torna-se importante a investigação do fenômeno do bullying entre os adolescentes que cumprem medidas socioeducativas de liberdade assistida.

Os jovens que cometem algum tipo de ato infracional possuem características específicas, como, por exemplo, a violação de normas e regras sociais, comportamento desviante das práticas culturais vigentes, dificuldades para se socializar, comportamento antissocial, envolvimento em brigas, impulsividade e humor depressivo. Tentativas de suicídio, ausência de sentimento de culpa, hostilidade, destruição de patrimônio público, vandalismo, rejeição por parte de professores e colegas, envolvimento com pares desviantes, baixo rendimento acadêmico, fracasso e evasão escolar também fazem parte desses sintomas (Cho et al., 2009; Fekkes et al., 2004; Gallo \& Williams, 2008; Rusby, Forrester, Biglan, \& Metzler, 2005; White \& Loeber, 2008). Essas características também podem ser encontradas nos envolvidos no bullying, reforçando a importância de investigar a relação entre o comportamento infracional em adolescentes e o fenômeno bullying (Bittencourt et al., 2009). Dessa forma, o objetivo desta pesquisa foi investigar o fenômeno do bullying em adolescentes que cumprem medida socioeducativa de liberdade assistida, conhecendo a percepção dos participantes sobre o bullying, a sua relação com o contexto escolar e o papel que os adolescentes desempenharam no bullying.

\section{Método}

\section{Delineamento e participantes}

Este estudo consistiu em uma pesquisa exploratória e qualitativa com adolescentes que cometeram ato infracional. Participaram deste estudo cinco adolescentes, com idades entre 16 e 17 anos, cursando entre a 7ํㅜ e a 9o série do Ensino Fundamental, que cometeram ato infracional e que estavam cumprindo medida socioeducativa de liberdade assistida em uma instituição não governamental de defesa aos 
direitos da criança e do adolescente, em uma cidade localizada no Sul do Brasil. Essa instituição é uma ONG que executa medidas socioeducativas em meio aberto (prestação de serviço à comunidade e liberdade assistida), aplicadas pelo Juizado da Infância e da Juventude aos adolescentes autores de atos infracionais. A partir de princípios pedagógicos, psicológicos, sociais e culturais, a entidade busca prevenir a reincidência do ato infracional, despertar a responsabilidade pelos seus atos no adolescente, construir em conjunto experiências positivas e novas referências, prevenindo a criminalidade e promovendo o desenvolvimento de uma consciência cidadã. Ela está conveniada a mais de 40 cidades da região central do Rio Grande do Sul. Para que a identidade dos participantes seja preservada, eles serão representados por letras, juntamente com as suas idades.

\section{Instrumentos e procedimentos}

Foi utilizada uma entrevista semiestruturada contendo questões que abordaram a relação dos adolescentes com a escola, o conhecimento e a percepção dos adolescentes sobre o bullying, a experiência do bullying e o tipo de papel que o adolescente teve nesse fenômeno. Primeiramente, foi realizado um contato preliminar com a instituição para verificar a possibilidade de a pesquisa ser efetuada no local. Após a autorização da direção da instituição, o projeto de pesquisa foi submetido e aprovado pelo Comitê de Ética em Pesquisa, do Centro Universitário Franciscano (registro CEP/UNIFRA n. 105.2010.3).

A equipe técnica da instituição que executa as medidas socioeducativas indicou os participantes. Inicialmente, o pesquisador participou de dois encontros com um grupo de jovens, com o intuito de possibilitar sua aproximação junto aos adolescentes. Após esses encontros foi feito um contato com cada um dos participantes, no qual a pesquisa foi apresentada e também averiguada a disponibilidade dos indicados. Com aqueles que aceitaram foi marcado um horário para a entrevista.

Os participantes assinaram um Termo de Assentimento, no qual foram garantidos o sigilo, a confidencialidade dos dados e a possibilidade de desistir da pesquisa a qualquer momento, sem que houvesse prejuízo para os adolescentes, além da informação de que os resultados finais do estudo estariam à disposição dos participantes. As entrevistas foram realizadas na própria $\mathrm{ONG}$, tiveram duração de aproximadamente 40 minutos e foram gravadas e transcritas para análise qualitativa dos dados.

\section{Análise dos dados}

Os dados foram analisados qualitativamente segundo a Análise de Conteúdo de Bardin (1977). Foram encontradas três categorias de análise:

1) Conhecimento sobre o bullying: esta categoria de análise reuniu dados sobre a visão dos adolescentes entrevistados sobre o bullying.

2) Relação dos adolescentes com a escola: esta categoria agregou informações sobre como é o convívio escolar e como são percebidas as relações que os adolescentes entrevistados vivenciam com seus colegas e com os membros do corpo docente.

3) Vivências e consequências do bullying: esta categoria incluiu os dados sobre a vivência dos adolescentes no bullying, o papel que eles desempenhavam e o seu entendimento em relação às consequências para os envolvidos nessa violência.

\section{Resultados e discussão}

\section{Conhecimento sobre o bullying}

Foi investigada a percepção e o conhecimento dos entrevistados quanto ao fenômeno do bullying. Dois participantes possuíam uma boa compreensão sobre o bullying, descrevendo o fenômeno como uma forma de discriminação ou perseguição entre os colegas. Também comentaram que indivíduos que possuem alguma característica diferente estão mais vulneráveis a sofrer algum tipo de perseguição. Esses aspectos podem ser constatados na fala do adolescente C (17 anos). Segundo ele, bullying "é como se fosse um... preconceito racial alguma coisa assim, tipo, pessoas gordas, isso aí. Assim, a pessoa fala sobre elas". Essa definição está de acordo com a apresentada em estudos científicos, como o de Fante e Pedra (2008) e Lopes, Aramis e Saavedra (2003), 
os quais afirmam que, no fenômeno do bullying, o autor mobiliza a opinião dos colegas contra uma vítima, por meio do uso de apelidos ou difamações, utilizados para ressaltar alguma característica considerada diferente.

Outros dois adolescentes não souberam falar do que se tratava o bullying, e somente após a definição ter sido explicada eles conseguiram identificar o problema como sendo algo conhecido. Já o entrevistado B (16 anos) confundiu o bullying com disputa entre pares, trazendo relatos de discussões entre estudantes.

Às vezes tem os da manhã que ficam na entrada do colégio. Pegando a entrada do colégio, e daí... daí tem como se envolverem, xinga uns aos outros, ou passa por eles olhando, passa encarando. Já querem mete briga. Daí os da tarde se juntam e vão brigá com os da manhã (Adolescente B).

A literatura tem indicado a existência de reforçadores dessas compreensões errôneas do fenômeno do bullying, como destaca Costantini (2004). Por mais que agressões físicas entre pares sejam manifestações de violência, a literatura demonstra que pouco tem sido feito para o seu combate (Fekkes et al., 2004). Costantini (2004) considera os adultos, educadores, como os principais responsáveis pela formação e consolidação dos comportamentos agressivos e das rotulações designadas para a vítima e também para o agressor. Outro aspecto que ele ressalta é a importância de o educador punir as atitudes dos agressores com firmeza, reforçando a necessidade de se manter o respeito entre os colegas e as regras de convívio social. Atitudes agressivas entre estudantes não deveriam ser toleradas pelos educadores e pais, contudo muitas vezes o são, especialmente quando as características do bullying são confundidas com dificuldades e disputas naturais das fases de desenvolvimento (Santos \& Grossi, 2008). Esses aspectos reforçam a necessidade de esclarecimento junto aos estudantes, professores e famílias para que se possa combater os comportamentos antissociais (Fekkes et al., 2004). Dessa forma, pode-se tentar evitar que os envolvidos nessas práticas venham a desenvolver algum tipo de comportamento problemático ligado à criminalidade (Costantini, 2004).

\section{Relacão dos adolescentes com a escola}

Os adolescentes demonstraram posicionamentos diferentes quanto às suas relações no contexto escolar. Três adolescentes relataram ter uma boa relação com os colegas e professores, um deles descreveu como problemático o convívio com os colegas, mas destacou o bom relacionamento com os professores, já o outro entrevistado considerou normal o seu convívio, apresentando um posicionamento neutro.

0 adolescente $\mathrm{C}$ (17 anos) mencionou que trocou de escola em decorrência da perseguição sofrida por parte dos colegas. 0 relato das perseguições associado ao fato de ter trocado de escola mostra claramente o papel de vítima vivenciado pelo adolescente. Se por um lado ele era perseguido pelos colegas, por outro procurou suporte na escola, encontrando apoio e incentivo com os professores, que o aconselharam a relevar o comportamento dos seus colegas, continuar a estudar e não mudar de escola, embora o adolescente o tenha feito. Esse apoio foi considerado importante pelo adolescente, pois ele sentia vergonha de compartilhar o problema com os pais e acabava guardando-o para si.

Eles começam a complica, daí começam assim... Daí briga, aconteceu briga com nós lá. E também coisa que não era comigo, né. Eu sofri muita coisa lá nesse colégio, daí eu saí de lá.... Com os professores era muito bom, tinha muita amizade com eles. Daí eles tavam sempre apoiando a gente a estuda. ... Até em casa fica difícil da gente fala. Falo, as vez, quando chegava a um ponto que não dava mais pra... aguentar, né (Adolescente C).

O apoio social é considerado uma das mais importantes dimensões do desenvolvimento e do bem-estar do ser humano, e um fundamental fator de proteção que pode mitigar os efeitos danosos de um evento estressor (Masten \& Garmezy, 1985; Werner \& Smith, 1992). Um estudo qualitativo demonstrou que a busca por apoio social foi considerada a estratégia de coping mais frequente entre crianças vítimas e não vítimas de bullying (Braga \& Lisboa, 2010). Contudo, o relato do adolescente denuncia o distanciamento entre ele e a família, que é buscada somente quando o jovem está no seu limite, como 
também a ineficiência da escola frente à ocorrência do fenômeno. Essas falhas devem ser trabalhadas para que o apoio social possa, de fato, atuar como proteção para o desenvolvimento da criança e do adolescente e incrementar os processos de resiliência do indivíduo (Bowes, Maughan, Caspi, Moffitt, \& Arseneault, 2010).

Apareceram duas falas nas quais os adolescentes admitiram já terem cometido algum ato de vandalismo ou depredação do patrimônio escolar, momento em que um deles agrediu verbalmente o professor. 0 entrevistado B (16 anos) relatou ter depredado a escola da seguinte maneira: "Quebra, dá pedrada!? Tava eu e meus colega. Tava numa época difícil, tava fugindo de casa, tava que mais... matando aula direto. Daí saia de noite com os piá, a mãe não sabia, eu não avisava". Essa atitude descrita pelo adolescente é um indicativo de uma conduta abusiva que poderá influenciar negativamente na formação dos valores sociais e, consequentemente, na formação do caráter do indivíduo, o que futuramente refletirá na sua vida pessoal, social, familiar e profissional (Fante \& Pedra, 2008). Por outro lado, esses comportamentos também podem estar associados ao momento de vida que eles estão vivenciando e às demandas individuais de cada um, fazendo com que essas reações desviantes possam ser interpretadas de outra forma, como a busca por limite, por atenção ou, até mesmo, como a dificuldade do adolescente em lidar de forma saudável com os conflitos externos e internos.

\section{Vivências e consequências do bullying}

Os cinco adolescentes entrevistados relataram ter vivenciado bullying e também reconheceram o tipo de papel assumido no fenômeno. Essa percepção ficou clara quando dois entrevistados descreveram ter participado de perseguições, apelidado pejorativamente e até mesmo agredido fisicamente os colegas, atuando no papel de agressor. Foi descrito o papel de agressor secundário pelo adolescente F (16 anos), que admitiu ter "entrado na onda" dos colegas quando esses colocavam apelidos ou perseguiam outros colegas. Xavier (2008) considera importante o reconhecimento dos agressores secundários, pois eles possuem o papel de cúmplices de quem toma a iniciativa das agressões, repetindo comportamentos agressivos ou obedecendo a ordens do agressor principal. No papel de vítima, tem-se o exemplo do adolescente C (17 anos), que precisou trocar de escola, pois não suportava mais as constantes perseguições e agressões que estava sofrendo de outros colegas. Mesmo com a mudança de escola, as perseguições persistiram, como se pode constatar no relato do jovem "pois é, daí eu troquei de colégio... e fui pro outro perto daquele lá. Daí... deu um tempo lá... os cara tavam lá também" (C, 17 anos).

Nos casos de vitimização de bullying a atenção deve ser maior, pois a literatura destaca que o impacto dessa pressão sobre os alunos com vínculos sociais fracos e que sofrem agressões é devastador e deve ser considerado como um fator de risco, favorecendo um possível envolvimento criminal futuro. Assim, estar atento ao bullying é fundamental, pois a adolescência é uma fase que favorece as transgressões e pode levar à formação de futuros psicopatas (Cullen et al., 2008).

Foi constatada também a flexibilidade no desempenho de papéis no bullying por parte dos adolescentes, visto que o mesmo adolescente relatou ter sido agressor em algumas situações e vítima em outras.

Antes de recebê meu apelido, eu apelidava qualquer um, ou chamava de qualquer coisa, e... e o que os outros chamavam eu também chamava, pra inticá entendeu, e como aquela pessoa não batia em mim daí que eu pegava e inticava mais, sabe. Mas depois que a gente é chamado por um apelido e não gosta e acaba pegando, ali que tu vê, "bah olha aí, fiz errado viu". Agora tu viu como é ruim, tu pegá e colocá apelido numa pessoa (Adolescente D).

A inversão dos papéis para o adolescente D (16 anos) fez com que ele vivenciasse sentimentos de medo e inferioridade, o que motivou uma mudança de comportamento referente ao bullying. Barker et al. (2008) destacam que, em estudos anteriores, o "valentão-vítima" tem apresentado uma vasta gama de problemas de ajustamento social. A dinamicidade do fenômeno deve ser considerada na construção de estratégias de intervenção e prevenção dessa forma de violência.

Cho et al. (2009) destacaram importantes relações entre desordem de comportamento e o 
fenômeno do bullying. Eles perceberam algumas características individuais, tais como problemas de comportamento, dificuldades escolares, rejeição entre pares e poucas relações sociais como sendo fatores de risco para o bullying. Eles ressaltam que os agressores tendem a ser desatentos, hiperativos e com pouca interação pró-social, já as vítimas tendem a apresentar comportamentos mais retraídos. As características do agressor podem ser percebidas no discurso do adolescente D (16 anos), que descreve sua interação social como sendo complicada: "bei eu me invocava por qualquer coisinha assim. Parecia que... eu não suportava, como vô te dize,... leva ah... leva coisas pra casa. Por exemplo, leva desaforo pra casa entendeu".

\section{Considerações finais}

0 bullying constitui-se em uma forma de comportamento agressivo que repercute no agressor, na vítima, em suas famílias e na sociedade. Ignorálo ou naturalizá-lo pode agravar a situação para a vítima. 0 presente estudo apresentou dados que enriquecem a discussão e ampliam a reflexão sobre esse fenômeno. 0 fato de a totalidade da amostra de jovens em conflito com a lei relatarem vivência de bullying é digna de reflexão. Embora seja uma amostra pequena, esse dado corrobora os estudos que relacionam bullying e o desenvolvimento de comportamento infracional, reiterando a importância de essa população ser foco de ações específicas de combate ao bullying. Para aqueles adolescentes que não apresentam psicopatia, pode-se desenvolver programas de habilidades sociais e de desenvolvimento da empatia, fazendo com que os comportamentos pró-sociais se sobressaiam aos comportamentos agressivos. Além disso, os adolescentes demonstraram confundir o bullying com disputas entre jovens. Tendo em vista que essa confusão também pode estar presente na sociedade, torna-se necessário um debate em diversos âmbitos sociais, a fim de esclarecer sobre o fenômeno junto aos adolescentes, adultos e instituições.

Ações de prevenção podem ser desenvolvidas no contexto escolar. A escola é o ambiente mais propício para alcançar crianças e adolescentes, então, deve-se usufruir desse local como uma ferramenta de auxílio no combate a esse tipo de violência. Dentro desse ambiente, estratégias direcionadas aos pais e aos educadores podem ser desenvolvidas, proporcionando, consequentemente, alterações em todos os âmbitos, visando à estruturação de uma rede de apoio aos jovens. Com essa ação, tanto a escola quanto a família atuarão como apoio social no caso da identificação do bullying, levando ao combate dessa violência.

A tendência do aumento de problemas comportamentais e a diminuição de habilidades pró-sociais entre os alunos com desordem de comportamento são dignas de ressalva quando se considera o bullying e a sua prevenção. Muitas características das vítimas (baixa autoestima, dificuldade de socialização, depressão) as colocam em risco de bullying, ao mesmo tempo, os estudantes com problemas de comportamento e com poucas habilidades pró-sociais também provocam um aumento no risco de envolvimento com esse fenômeno (Cho et al., 2009; Guerra et al., 2011). A identificação da vivência de bullying pelos jovens deve ocorrer por meio da observação por parte dos pais, dos educadores e da escola. Todos os envolvidos devem ficar atentos às mudanças atípicas no comportamento das crianças e/ou dos adolescentes. Com essa percepção será possível intervir precocemente na ocorrência desse fenômeno, evitando consequências mais graves no desenvolvimento dos indivíduos envolvidos (Almeida et al., 2008).

Com o intuito de combater a violência no ambiente escolar, Almeida et al. (2008) incentivam a implantação de programas de combate ao bullying nas escolas, visto que eles têm apresentado resultados satisfatórios na redução dos casos de bullying. Contudo, para que o programa seja eficaz, é importante que a família esteja atenta às mudanças de comportamento dos filhos, além de os educadores possuírem conhecimentos suficientes para reconhecer e intervir quando esse tipo de violência ocorrer no ambiente escolar.

Outro aspecto que pode ser considerado como uma medida de prevenção e de combate ao bullying é o envolvimento dos próprios jovens. Nesse sentido, profissionais da psicologia podem proporcionar espaços de esclarecimento sobre esse fenômeno e criar discussões que desenvolvam o senso crítico nos jovens, auxiliando na conscientização sobre as consequências que essa violência pode trazer ao outro. Além disso, a psicologia pode abrir portas para que todos os envolvidos no bullying (estudantes, famílias, escolas e sociedade) possam criar 
conjuntamente alternativas para prevenir e combater esse fenômeno.

É importante destacar as limitações do estudo relacionadas à impossibilidade de inclusão dos familiares e educadores nas entrevistas realizadas. Faz-se necessário que mais pesquisas sejam realizadas, incluindo esses importantes elementos do fenômeno do bullying, de forma que possa haver uma triangulação dos dados. Aspectos associados aos processos de resiliência por parte das vítimas de bullying também devem ser estudados com mais atenção. Além disso, sugere-se a realização de estudos com amostras mais diversificadas, compostas por adolescentes de diferentes faixas etárias e sexo.

A presente pesquisa mostrou a importância de se discutir o tema bullying, e que é imprescindível que a rede de apoio também esteja envolvida. Com o esforço conjunto dos adolescentes, famílias, educadores e profissionais da psicologia essa violência poderá ser discutida de forma mais ampla e combatida de forma mais eficaz.

\section{Referências}

Almeida, A., Lisboa, C., \& Caurcel, M. J. (2007). ¿Por que ocurre los malos tratos entre iguales? Explicaciones causales de adolescentes portugueses y brasileños. Interamerinan Journal of Psychology, 41(2), 107-118.

Almeida, K. L., Silva, A. C., Campos, J. S. (2008). Importância da identificação precoce da ocorrência do bullying: Uma revisão de literatura. Revista de Pediatria, 9(1), 8-16.

Associação Brasileira de Proteção à Criança e Adolescente - ABRAPIA. (2007). Programa de redução do comportamento agressivo entre estudantes.Recuperado em 21 de abril, 2010, de www.bullying.com.br

American Psychiatric Association - APA. (2002). Manual diagnóstico e estatístico de transtornos mentais: DSMIV-TRTM. Porto Alegre: Artmed.

Bardin, L. (1977). Análise de conteúdo. Lisboa: Edições 70.

Barker, E. D., Arseneault, L., Brendgen, M., Fontaine, N., \& Maughan, B. (2008). Joint development of bullying and vitimization in adolescence: Relations to delinquency and self-harm. Journal of the American Academy of Child and Adolescent Psychiatry, 47(9), 1030-1038.
Bittencourt, A. A., Aerts, D. R. G. C., Alves, G. G., Palazzo, L., Monterio, L., Vieira, P. C., \& Freddo, S. L. (2009). Sentimento de discriminação em adolescentes: Prevalência e fatores associados. Revista de Saúde Pública, 43(2), 236-245.

Bowes, L., Maughan, B., Caspi, A., Moffitt, T. E., \& Arseneault, L. (2010). Families promote emotional and behavioural resilience to bullying: Evidence of an environmental effect. Journal of Child Psychology and Psychiatry, 51(7), 809-817.

Braga, L. L., \& Lisboa, C. (2010). Estratégias de coping para lidar com o processo do bullying: Um estudo qualitativo. Interamerinan Journal of Psychology, 44(2), 321-331.

Cho, J., Hendrickson, J. M., \& Mock, D. R. (2009). Bullying status and behavior patterns of preadolescents and adolescents with behavioral disorders. Education and Treatment of Children, 32(4), 655-671.

Costantini, A. (2004). Bullying, como combatê-lo? São Paulo: Itália Nova Editora.

Cullen, F. T., Unnever, J. D., Hartman, J. L., Turner, M. G., \& Agnew, R. (2008). Gender, bullying victimization, and juvenile delinquency: A test of general strain theory. Victims and Offenders, 3(4), 346-364.

Esperon, P. S. M. (2004). "Bullying": Comportamento agressivo entre colegas no ambiente escolar. Pediatria Moderna, 60(2), 67-76.

Fante, C., \& Pedra, J.A. (2008). Bullying escolar: Perguntas e respostas. Porto Alegre: Artmed.

Francisco, M. V., \& Libório, R. M. C. (2008). Um estudo sobre bullying entre escolares do ensino fundamental. Psicologia: Reflexão e Crítica, 22(2), 200-207.

Fekkes, M., Pijpers, F. I. M., \& Vanhorick, S. P. (2004). Bullying: Who does what, when and where? Involvement of children, teachers and parents in bullying behavior. Health Education Research: Teory and Practice, 20(1), 81-91.

Gallo, A. E., \& Williams, L. C. A. (2008). A escola como fator de proteção à conduta infracional de adolescentes. Cadernos de Pesquisa, 38(133), 41-59.

Guerra, N., Williams, K, \& Sadek, S. (2011). Undestanding bullying and victimization during childhood and adolescence: A mixed methods study. Child Development, 82(11), 295-310. 
Lopes, N., Aramis, A., \& Saavedra, L.H. (2003). Diga não para o bullying: Programa de redução do comportamento agressivo entre estudantes. Rio de Janeiro: ABRAPI.

Masten, A. S., \& Garmezy, N. (1985). Risk, vulnerability, and protective in developmental psychopathology. In: B. B. Lahey \& A. E. Kazdin (Org.), Advances in clinical child psychology (pp. 1-52). New York: Plenum Press.

Neto, A. A. L. (2005). Bullying: Comportamento agressivo entre estudantes. Jornal de Pediatria, 81(5), 164-172.

Rusby, J., Forrester, K., Biglan, A., \& Metzler, C. (2005). Relationship between peer harassment and adolescent problem behaviors. The Journal of Early Adolescence, 25(4), 453-477.
Santos, A. M., \& Grossi, P. K. (2008). Fenômeno bullying: Desvendando esta violência nas escolas públicas de Porto Alegre. Revistas Textos \& Contextos, 7(2), 286-301.

Xavier, N. F., (2008). Análise jurídica e psicossocial da ocorrência de bullying sob a ótica da doutrina da proteção integral. Monografia, Universidade Regional Integrada do Alto Uruguai e das Missões Campus Santiago, Santiago (RS).

Werner, E. E., \& Smith, R. (1992). Overcomming the odds: High risk children from birth to adulthood. New York: Cornell University Press.

White, N., \& Loeber, R. (2008). Bullying and special education as predictors of serious deliquency. Journal of Research in Crime and Deliquency, 45(4), 380-397. 